Cognitive Schemas as Longitudinal Predictors of Self-Reported Adolescent Depressive Symptoms and Resilience

$$
\text { by }
$$

Jordan S. Friedmann

\author{
A Thesis \\ Presented to \\ The University of Guelph
}
In partial fulfilment of requirements for the degree of
Master of Arts
in
Psychology

Guelph, Ontario, Canada

(C) Jordan S. Friedmann, July, 2013 


\section{ABSTRACT \\ COGNITIVE SCHEMAS AS LONGITUDINAL PREDICTORS OF SELF-REPORTED ADOLESCENT DEPRESSIVE SYMPTOMS AND RESILIENCE}

Jordan S. Friedmann
University of Guelph, 2013
Advisor:

Dr. Margaret N. Lumley

Given that depression risk intensifies in adolescence, examining the course of depressive symptoms during the shift from childhood to adolescence is important for expanding knowledge about the etiology of depression. From a cognitive-developmental perspective, this study examined the stability of both positive and negative schemas in adolescence and whether these schemas could prospectively predict depressive symptoms and resilience in youth. One hundred ninety-eight participants (48 percent boys, 52 percent girls) between the ages of 9 and 14 were recruited from 4 elementary schools to complete measures of youth depressive symptoms, resilience, and schema content and organization. Those who consented to be re-contacted for a follow-up study were contacted one to three years later to complete the same measures online. The Time 2 sample consisted of 50 participants (54 percent boys, 46 percent girls). Negative and positive schema content and structure were stable over time. Depressive symptoms at Time 2 were hypothesized to be predicted by strong negative and weak positive schema content, tightly interconnected negative schema organization, and loosely interconnected positive schema organization at Time 1. The opposite patterns of association were hypothesized between schema content and structure and resilience. After controlling for age, sex and depressive symptoms /resilience at Time 1, negative schema content was the only significant predictor of depressive symptoms and resilience at Time 2 . Implications for cognitive theories and clinical practice are discussed. 


\section{Acknowledgements}

I would like to express my sincere gratitude to the people who have supported me throughout the process of completing my thesis. First, I would like to thank my supervisor, Dr. Margaret Lumley, for her advice, guidance, and support throughout the past two years. I would like to thank my committee member, Dr. Stephen Lewis, for his insightful feedback and timely review of my thesis. I would also like to thank Dr. Heidi Bailey for chairing my defence and providing me with helpful comments. I would like to thank Dr. David Stanley for his advice with regards to some of the statistical analysis involved in my thesis. Additionally, I would like to thank the resilient youth research group lab members who helped with the data collection, as well as, the participants who were willing to share their time during the process. Finally, I would like to thank my family and friends who have supported me throughout the entire process. In particular, I would like to thank my partner, Sean, for his love, patience, and support. 


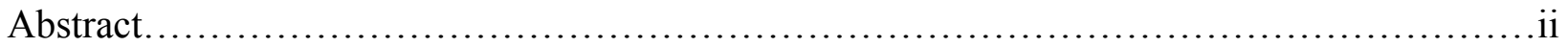

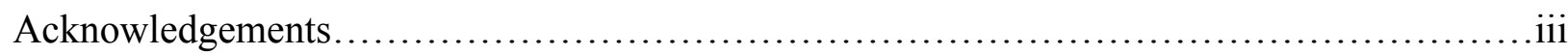

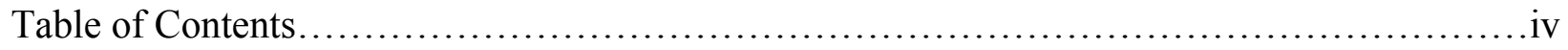

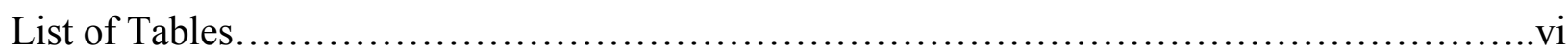

List of Appendices.................................................................

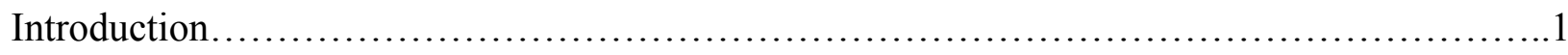

Cognitive Schemas and Youth Depression......................................

Cognitive Schema Organization in Youth.......................................6

Positive Schemas and Depression........................................... 8

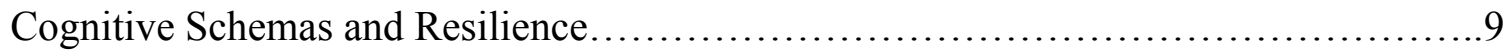

Stability of Cognitive Risk for Depression................................... 11

Present Research.........................................................13

Research Questions and Hypotheses.......................................13

Method........................................................................ 15

Participants............................................................

Measures..............................................................16

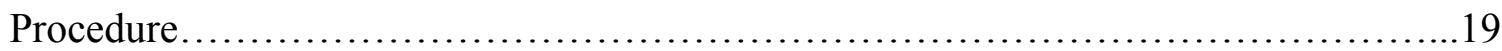

Results...................................................................... 20

Preliminary Analyses....................................................20

Stability of Schemas in Youth.............................................. 24

Schemas as Prospective Predictors of Depressive Symptoms........................25

Schemas as Prospective Predictors of Resilience................................27 


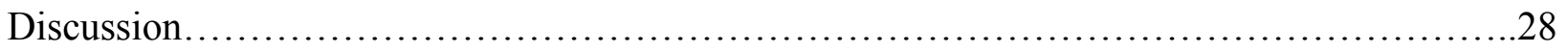

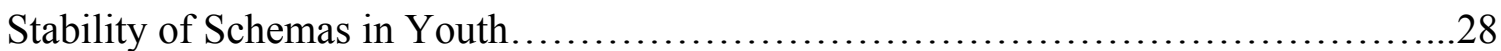

Schemas as Prospective Predictors of Depressive Symptoms.......................29

Schemas as Prospective Predictors of Resilience................................. 30

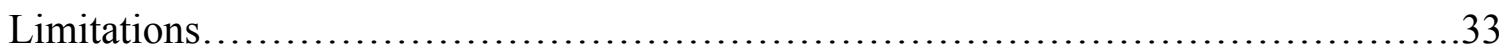

Future Directions and Implications..............................................

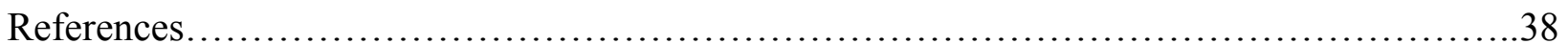




\section{List of Tables}

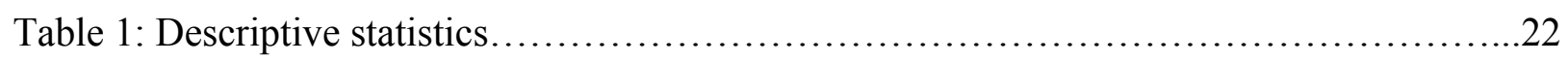

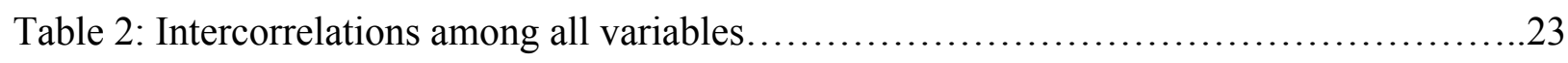

Table 3: Paired samples t-tests: Examining differences in variables over time...............25

Table 4: Correlations and partial correlations of variables at Time 1 with depressive symptoms

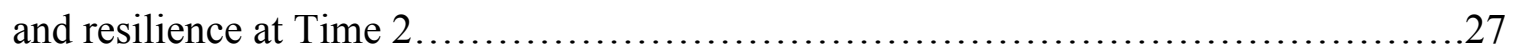




\section{List of Appendices}

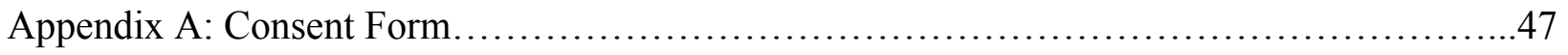

Appendix B: Resilience Scale.................................................49

Appendix C: Schema Questionnaire for Children....................................50

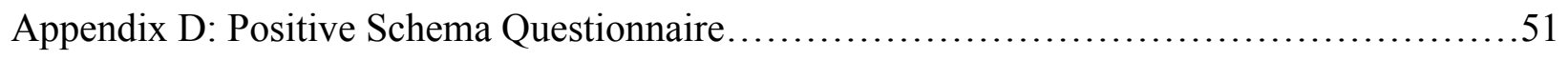

Appendix E: Psychological Distance Scaling Task...................................53 


\section{Cognitive Schemas as Longitudinal Predictors of Self-Reported Adolescent Depressive}

\section{Symptoms and Resilience}

Examining the course of depressive symptoms during the shift from childhood to adolescence is important for expanding theoretical knowledge about the etiology of depression. As children progress through adolescence, mental health disorders become significantly more prevalent (Abela \& Hankin, 2008), with depression rates rising six-fold between the ages of 10 and 14 (Hankin et al., 1998), and annual incidence rates of depression doubling from age 13 (12\%) to age 15 (3-7\%; Lewinsohn, Rohde, \& Seeley, 1998). By age 14, nine percent of adolescents will have had at least one severe episode of depression (Lewinsohn, Rohde, Seeley, \& Fischer, 1993), and by the age of 19, 28 percent (Lewinsohn et al., 1998). The prevalence of clinically significant subsyndromal depressive symptoms can be as high as 20 to 50 percent (Kessler, Avenevoli, \& Merikangas, 2001). Adolescents with subsyndromal depressive symptoms resemble adolescents with major depression on many important outcomes, including heightened risk of future depression and suicidal behaviours (Fergusson, Horwood, Ridder, \& Beautrais, 2005; Gotlib, Lewinsohn, \& Seeley, 1995), degree of comorbidity with other mental disorders (e.g., anxiety and disruptive behaviour disorders), and functional impairment (Gonzalez-Tejera et al., 2005). Early depressive symptoms generally predict more severe mood disorders later in life (Abela \& Hankin, 2008). For example, depressive symptoms in adolescence significantly increase risk for a diagnosis of Major Depressive Disorder (MDD) later in life (Georgiades, Lewinsohn, Monroe, \& Seeley, 2006).

Many adults diagnosed with MDD in early adulthood trace the onset of their symptoms to adolescence (Kim-Cohen et al., 2003). For instance, in a longitudinal study, seventy-five percent of adults with diagnosed major depression at age 26 traced the onset of their disorder to 
adolescence (Kim-Cohen et al., 2003). In addition, depressive symptoms in adolescence have been linked to psychosocial problems affecting various domains of life, such as dropping out of school, drug use, and deviant behaviour (e.g., theft; Kandel \& Davies, 1986). Moreover, early depressive episodes are associated with high rates of depression recurrence (e.g., Kovacs, 1996; Lewinsohn et al., 1998; Rutter, Kim-Cohen, \& Maughan, 2006). Likewise, adolescent depression is associated with suicidal ideation and suicidal attempts (Fergusson et al., 2005; Lewinsohn et al., 1998). Thus, understanding depression in its early adolescent stages is a strong research priority.

Cognitive-developmental frameworks have been useful in elucidating risk for depression in adolescence. Within such frameworks, cognitive schemas (an important aspect of one's overall self-concept or identity) are conceptualized as core organizing structures in the mind and are theorized to influence how information is interpreted and processed (Ingram, Miranda, \& Segal, 1998). Within this literature, cognitive schemas with themes of loss, defectiveness, and dependence have been identified as important vulnerability factors in the etiology of depression (Beck, 1967; 1987; Dozois \& Beck, 2008). More recently, positive cognitive schemas (i.e., positive core beliefs about self, e.g., self-efficacy, worthiness) have also been identified as important protective factors for promoting resilience in a sample of early adolescents (Keyfitz et al., 2012). The current study employed a cognitive-developmental framework to examine the stability of cognitive schemas in youth, and whether either positive or negative cognitive schemas could prospectively predict depressive symptoms and resilience in an adolescent sample.

Beck's cognitive theory of depression $(1967 ; 1987$; Dozois \& Beck, 2008) suggests that cognitive schemas develop early in childhood as a result of interactions with close others (e.g., 
caregivers), and influence how individuals navigate the world, interpret events, and respond in social situations. Schemas formed in childhood can be dormant until activated by a significant triggering event (Beck, 1987). While automatic thoughts and cognitive distortions are conceived as spontaneous thoughts associated with negative affect, it is the underlying assumptions and schemas that are thought to lead to the manifestation of psychological disorders such as depression (Beck, 1987; Clark, Beck \& Alford, 1999). Thus, cognitive-developmental theories are diathesis-stress theories, asserting that depression results from an interaction between a cognitive vulnerability factor and an environmental stressor such as a negative life event (Ingram, Miranda, \& Segal, 1998). Following an environmental stressor, a vulnerability factor is an enduring and individual feature that increases the likelihood of developing psychopathology for youth who are susceptible (Ingram et al, 1998).

Cognitive schemas are defined as mental representations of oneself (Beck, 1987), and consist of both content and organization aspects (Beck, 1967). Cognitive schema content refers to core self beliefs, which can be positive (e.g., "I'm a good person") or negative (e.g., "I'm a failure"; Beck, 1967). Cognitive schema organization refers to how this schema content is represented or stored in one's mind in relation to other schema content (Beck, 1967). Schema content is theorized to vary in its interconnectivity with related content (i.e., some schemas may be more tightly or loosely interconnected to related content than others; Dozois \& Beck, 2008). Positive and negative schema content may be organized differently in one's mind such that they may vary in their interconnectivity with other schema content (Dozois \& Beck, 2008). The manner by which positive and negative schemas are organized can be referred to as schema structure; accordingly, there is both positive schema organization (PSO) and negative schema organization (NSO). 
Cognitive theory suggests that when a schema (or self-belief) is activated, it triggers the activation of related schema content (Ingram, 1984). Tightly interconnected schemas are thought to be more consolidated, and therefore, activate related content more easily than loosely interconnected schemas (Ingram, 1984). Similarly, schemas containing many interconnected self-beliefs would be activated more often than schemas containing few beliefs (Ingram et al., 1998). Therefore, individuals with tightly organized positive schemas may have easily activated interrelated positive self-beliefs such as being friendly, caring, kind, helpful, brave, proud, and talented. Conversely, individuals with tightly organized negative schemas may have easily activated interrelated negative self-beliefs such as being shy, alone, unwanted, unloved, boring, stupid, and ugly, which may facilitate the activation of negative affective states including depressed mood. Similarly, individuals with loosely organized schemas may have difficulty activating related content and associated positive affective states. Therefore, schema organization has been theorized to have implications for positive functioning and psychopathology.

\section{Cognitive Schemas and Youth Depression}

Decades of research demonstrate that depression is strongly associated with and predicted by negative schema content in adult samples (see Dozois \& Beck, 2008 for a review). Although most research on early cognitive risk for depression was conducted with adults, there now exists a large body of work that has examined cognitive risk for depression amongst youth. Thus, numerous cross-sectional and longitudinal studies support negative schema content as an important predictor of depression in youth (Abela \& Sullivan, 2003; Carter \& Garber, 2001; Garber, Weiss, \& Shanley, 1993; Hammen \& Zupan, 1984; Hankin, Abramson, Miller, \& Haeffel, 2004; Kercher, Rapee, \& Schniering, 2009; Lewinsohn, Joiner, \& Rohde, 2001; Lumley 
\& Harkness, 2007; Timbremont \& Braet, 2004). For example, Hammen and Zupan (1984) found that children with depressive symptoms as early as grades 3 to 6 endorsed more negative selfdescriptive words than children without symptoms of depression. In a sample of almost 900 seventh grade girls, those who had high levels of negative schema content (particularly with themes of failure) were at a higher risk for depression than those who had lower levels of such content (Kercher et al., 2009). In another study of nearly 700 students in grades 7 to 12 , negative schema content was correlated with depressive symptoms at a comparable or greater magnitude than that which is typically evidenced in adult literature (Garber et al., 1993).

Regarding the diathesis stress element of cognitive theories, prospective studies also suggest that negative schema content interacts with negative life events to predict depression. In a sample of 200 undergraduate students, cognitive vulnerability to depression predicted depressive symptoms both five weeks later and two years later (Hankin et al., 2004). A longitudinal study of 1500 senior high school students found support for negative schema content as a risk factor for major depressive disorder, particularly for adolescents who experienced negative life events (Lewinsohn et al., 2001). Similarly, a prospective study of nearly 200 students in seventh grade found that negative schema content at Time 1 was associated with depressive symptoms six weeks later (Abela \& Sullivan, 2003).

While cognitive schemas are one aspect of cognition identified as an important vulnerability factor in the etiology of depression, another related aspect of cognitive vulnerability to depression is attributional style. Individuals with a negative attributional style are theorized to attribute negative events to internal, global, and stable causes, and positive events to external, specific, and unstable causes (Abramson, Seligman, \& Teasdale, 1978). Conversely, individuals with a positive attributional style are theorized to attribute positive events to internal, global, and 
stable causes, and negative events to external, specific, and unstable causes (Abramson et al., 1978). According to hopelessness theory of depression, a negative attribution style leads to depression due to a style of interpreting events such that negative events are attributed to internal (e.g., "it's my fault"), global (e.g., "everything is ruined"), and stable (e.g., "this will last forever") causes, and positive events are attributed to external (e.g., "it was luck"), specific (e.g., “just this time"), and unstable (e.g., things will change) causes (Abramson, Metalsky, \& Alloy, 1989). Many longitudinal studies have linked negative attributional styles to the onset and maintenance of depression and depressive symptoms in adolescents. For example, a longitudinal study of nearly 500 adolescent girls found evidence that for girls with a negative attributional style (compared to girls with a positive attributional style), stressors predicted both the onset of a major depressive episode, and increases in depressive symptoms (Bohon, Stice, Burton, Fudell, \& Nolan-Hoeksema, 2008). Similarly, a six-year longitudinal study of 240 adolescents, who were first assessed in grade 6 , found that the first onset of a major depressive episode was predicted by high interpersonal stress (regardless of negative cognitions) or low interpersonal stress combined with high negative cognitions (Carter \& Garber, 2011). In addition, higher levels of interpersonal stress predicted higher levels of depressive symptoms for adolescents with more negative cognitions, but not for adolescents with less negative cognitions (Carter \& Garber, 2011). Taken together, there is strong support that the cognitive vulnerability-stress model predicts both the onset of major depression, and increases in depressive symptoms (Bohon et al., 2008; Carter \& Garber, 2011).

\section{Cognitive Schema Organization in Youth}

Schema organization refers to how self-beliefs are represented or stored in one's mind, or how schema content is organized in relation to other content (Beck, 1967). Negative schemas 
may be particularly problematic when they are tightly interconnected because they allow related beliefs to be activated more easily in an associated network (Collins \& Loftus, 1975). Adult research demonstrates that schema organizations of individuals with depression differ from individuals without depression (Dozois \& Dobson, 2001b; 2003; Dozois \& Frewen, 2006). More specifically, research suggests that a depressotypic pattern consists of tightly interconnected negative schema organization and loosely interconnected positive schema organization (Dozois, 2007; Dozois \& Dobson, 2001a; 2001b; 2003, Dozois \& Frewen, 2006). Individuals who have experienced more episodes of depression show more tightly interconnected negative schema organization than individuals who have experienced fewer episodes (Dozois \& Dobson, 2003). Individuals who have experienced more episodes of depression also show more loosely interconnected positive schema organization, compared to individuals who have experienced fewer depressive episodes (Dozois \& Dobson, 2003).

While schema content has been found to influence emotional disorders in adolescents (e.g., Lumley \& Harkness, 2007), little research has examined how schema content is organized in youth, and how schema organization relates to depression and importantly, to resilience in youth. Similar to research findings with adults, there are two studies that examine cognitive organization in adolescence, and both suggest that similar to adult research, there are identifiable schematic organization differences between depressed and non-depressed adolescents (Dozois, Eichstedt, Collins, Phoenix, \& Harris, 2012; Lumley, Dozois, Hennig, \& Marsh, 2011). More specifically, this research suggests that elevated depression symptoms in early adolescence (Lumley et al., 2011) or a diagnosis of MDD (Dozois et al. 2012) is associated with tightly interconnected negative schema organization and loosely interconnected positive schema organization. 


\section{Positive Schemas and Depression}

As discussed above, a plethora of research has focused on the relation between negative schemas and depression; however, much less research has examined associations between positive schemas and depression, particularly among youth. Although often less emphasized in cognitive developmental models of risk for depression, it is important to examine positive schemas and their relation to depression. McClain and Abramson (1995) suggest that the lack of positive schemas may be more important for understanding the etiology of depression than the presence of negative schemas. For example, in their study of undergraduate students, levels of dysphoria were distinguishable by levels of positive schemas, but not negative schemas (McClain \& Abramson, 1995). Similarly, while individuals with depression show evidence of positive schemas, they have been hypothesized to be more loosely interconnected, and therefore more difficult to activate than negative schemas (Dozois \& Dobson, 2001a). Although comparatively sparse, some research addresses this topic amongst youth. For example, in one early study exploring self-concept and depression risk, 8 to 11 year-old children with symptoms of depression endorsed less positive self-descriptive words than children without symptoms of depression (Hammen \& Zupan, 1984). Gencoz and colleagues (2001) found that a lack of positive schema content in a sample of 9 to 17 year-olds was a specific cognitive feature of depression, rather than other internalizing disorders (i.e., anxiety). Most recently, in a sample of 170 adolescents aged 9 to 14 , positive schema content was negatively related to depression and importantly, explained more variance in youth depressive symptoms than negative schema content (Keyfitz et al., 2012). In particular, these results suggest that the absence of positive schemas may be a particularly important predictor of depressive symptoms among youth (Keyfitz et al., 2012). 


\section{Cognitive Schemas and Resilience}

Clinical psychology research has typically focused on risk factors and vulnerability in psychopathology, and improving negative functioning by reducing distress (Wood \& Tarrier, 2012). However, more recently, those espousing a positive clinical psychology approach have argued that examining protective factors and increasing positive functioning and wellbeing is an equally important goal (Masten, 2001; 2007; Wood \& Tarrier, 2012). Since vulnerability and resilience to depression are linked constructs (Haeffel \& Grigorenko 2007), and positive and negative well-being are strongly interrelated more generally, integrating positive topics into psychopathology research addresses the need for well-rounded theories of psychopathology and a balanced focus on positive and negative aspects of functioning (Wood \& Tarrier, 2010). Ultimately, a better understanding of both risk and resilience may help promote resilience and prevent psychopathology (Masten, 2007; 2011).

While considerable research has examined negative schemas and risk for depression, far less research has examined how schemas figure for understanding resilience. Similar to previous studies (e.g., Keyfitz et al., 2012), this study conceptualized resilience as self-reported capacity to cope or effectively manage self-appraised life difficulties (e.g., health problems) or stressful life events (e.g., death of a family member) adaptively. It is important to note that resilience is considered an ordinary developmental process that stems from normative human resources rather than unusual or extraordinary qualities (Masten, 2001). While positive schemas focus on core beliefs about the self which are theorized to be essential (or unconditional) aspects of self (Clark et al., 1999), resilience is anchored to the process of responding to stress in the environment and captures beliefs about how one copes with stressful life events. Thus, in the current study resilience is defined as ones internal resources (e.g., personal strengths, feelings, attitudes) to 
cope with adversity. Although resilience and positive schemas are related constructs, research to date suggests they are distinct (Keyfitz et al., 2012). Even after controlling for resilience when examining positive schemas as a predictor of depression, positive schemas were found to predict unique variance in depression (Keyfitz et al., 2012).

Researchers have begun to integrate resilience constructs into cognitive developmental theories of risk for depression (Hjemdal, Aune, Reinfjell, Stiles, \& Friborg, 2007; Hjemdal, Vogel, Solem, Hagen, \& Stiles, 2011; Keyfitz et al., 2012; Mak, Ng, \& Wong, 2011) to better understand and prevent psychopathology (Masten, 2001; 2007; 2011). In studies of nearly 400 younger adolescents (aged 13 to 15; Hjemdal et al., 2007), and 300 older adolescents (aged 14 to 18; Hjemdal et al., 2011), higher levels of resilience were associated with lower levels of depressive symptoms. Interestingly, in a sample of 1400 university students, positive cognitions mediated the relationship between resilience and depression such that students with higher levels of resilience had more positive cognitions and lower levels of depressive symptoms (Mak et al., 2011).

Since resilience may be an important protective factor against the development of depression symptoms and disorder, understanding how schemas influence this positive cognitive process is an important research goal, yet very little research has examined this question. Keyfitz and colleagues (2012) found that positive schema content was strongly associated with resilience in a cross-sectional study of early adolescents recruited from elementary schools. They also found that negative schema content did not significantly contribute to resilience (Keyfitz et al., 2012). However, no research to date has examined cognitive schemas as prospective predictors of resilience in youth. In addition, the current study integrates positive functioning and psychopathology in an adolescent research design. Incorporating resilience in 
the current study may shed light on the prevention of depression by buffering the impact of negative events on the development of depressive symptoms, and may inform how resilience can be promoted in non-clinical populations (Wood \& Tarrier, 2010).

\section{Stability of Cognitive Risk for Depression}

Beck (1967) posited that cognitive schema organization is an enduring characteristic.

Previous research suggests that depressotypic cognitive organization is evident by early adolescence (Lumley et al., 2011). However, given the importance of identity formation and exploration during adolescence (Brinthaupt \& Lipka, 2002), schemas may not be stable during this developmental stage. Furthermore, risk factors may vary by sex during adolescence because sex differences in vulnerability to depression begin to emerge during this time period (Twenge \& Nolen-Hoeksema, 2002). However, cognitive developmental research suggests that schemas likely stabilize by sixth grade and continue to become more stable throughout adolescence (Abela \& Hankin, 2008; Hankin \& Abela, 2005; Hankin, 2008). Hankin (2008) recently found support for the stability of negative cognitive style in a prospective study of early and middle adolescents (aged 11 to 17). However, previous research has not considered the development of positive schemas nor has research examined schemas more broadly, considering both structural and content aspects. Examining the stability of cognitive vulnerability to depression may help inform timing and suitability of particular cognitive behavioural interventions for depression that typically focus on schemas.

In a longitudinal study, adults with MDD showed equal bias toward negative content at Time 1 and 2 (6 months later), and a decrease in reaction time to positive content, indicating the stability of negative content biases (Dozois \& Dobson, 2001a). These findings also suggest that as the duration of depressive episodes increase, individuals may be more inclined to disregard 
positive information, and intensify their bias toward negative content (Dozois \& Dobson, 2001a). In addition, there is support for stable negative schema organization among adults with depression (Dozois \& Dobson, 2001a). Furthermore, Dozois (2007) confirmed that negative schema organization may remain relatively stable over time among adults, even after depression is reduced via treatment. Therefore, adult research suggests that negative schema organization is an important and stable vulnerability factor in the course of depression (Dozois \& Dobson, 2001a).

Positive schema organization has been found to be less stable in adulthood. Individuals with depression may have more loosely interconnected positive schema organization compared to a control group (Dozois, 2007). However, this research suggests that positive schema organization becomes more tightly interconnected during remission of depressive symptoms (Dozois, 2007; Dozois \& Dobson, 2001a). While research with adults shows that during remission from depression, negative cognitive organization may remain relatively stable and positive cognitive organization may improve (Dozois, 2007), no research to date has examined the stability of schema organization in youth.

Examining the stability of schemas among youth is important because patterns of schema stability may differ for youth, and may change throughout their progression into adolescence and adulthood. Some research suggests that positive constructs (e.g., positive schema content and structure) might be important early predictors of vulnerability to depression in youth (e.g., Keyfitz et al., 2012). In addition, examining the stability of schemas has important clinical implications. For example, cognitive behaviour therapy is one of the most used and supported evidence-based treatments for youth depression and focuses on identifying and modifying maladaptive cognitions. Therefore, learning about which types of cognitions are most 
problematic and most helpful for promoting positive development at various ages may be clinically relevant.

\section{Present research}

Longitudinal data would significantly contribute to the theoretical understanding of the etiology of depression in youth. While research among youth has demonstrated that schema content prospectively predicts the development of depression (e.g., Hankin, Lakdawalla, Lee, Grace, \& Roesch, 2004), and schema organization has been shown to predict depressive symptoms in youth in cross-sectional studies (Dozois et al., 2012; Lumley et al., 2011), no research to date has examined the stability of schema organization among youth nor has research examined schema organization as a prospective predictor of depressive symptoms and resilience among youth. In addition, research findings on schema content and organization from research conducted with adults may not be generalizable to youth; therefore the current study may help to address these gaps and may enhance the understanding of depression in its early adolescent stages, a time when many individuals experience their first depression symptoms or disorder.

This study examined schemas in relation to depressive symptoms, but also to a theorized protective factor, resilience. This approach responds to the call to jointly consider psychopathology and positive psychology constructs within the same research studies (Wood \& Tarrier, 2010). It is important to look at positive functioning in addition to negative functioning in order to better understand the whole person and ultimately how to best promote resilience in the context of risk for depression.

\section{Research Questions and Hypotheses}

This study addressed several interrelated research questions and hypotheses described below: 
1. Stability of Schemas in Youth. The first goal of this study was to examine the stability of positive and negative schema content and organization in adolescence, an important time for depression vulnerability. While one previous study found support for the stability of a negative cognitive style in a prospective study of early and middle adolescents (aged 11 to 17; Hankin, 2008), previous research has not considered the development of positive schemas nor has research considered both schema structure and content in one study. Since cognitive schemas are theorized to develop early in childhood (Beck, 1967), by early adolescence, schema structure and content may be quite stable. Conversely, it may be that schemas are not stable by early adolescence because of the emphasis on identity formation and exploration during this developmental phase (Brinthaupt \& Lipka, 2002). In addition, sex differences in vulnerability to depression begin to emerge in adolescence (Twenge \& Nolen-Hoeksema, 2002), suggesting that risk factors may vary by sex during this time period. Given the lack of previous empirical support regarding schema stability in adolescence, analyses of schema stability in this study were of an exploratory nature.

2. Schemas as Prospective Predictors of Depressive Symptoms. The second goal of this study was to examine whether schema content and organization at Time 1 prospectively predict depressive symptoms at Time 2. It was hypothesized that schema content and organization at Time 1 would prospectively predict youth-reported depressive symptoms at Time 2. More specifically, it was hypothesized that depressive symptoms at Time 2 would be predicted by strong negative and weak positive schema content, tightly interconnected negative schema organization, and loosely interconnected positive schema organization at Time 1.

3. Schemas as Prospective Predictors of Resilience. Finally, this study examined whether schema content and organization at Time 1 prospectively predicted youth-reported 
resilience at Time 2. It was hypothesized that resilience at Time 2 would be predicted by strong positive and weak negative schema content, tightly interconnected positive schema organization, and loosely interconnected negative schema organization at Time 1. To examine cognitive schemas as prospective predictors of depressive symptoms and resilience, age, sex and mood at Time 1 were controlled for in the analyses.

This study may contribute to the cognitive developmental models of the etiology of depression and may also be uniquely relevant for increasing understanding about how cognitive schemas relate to resilience in youth, a topic that has been largely neglected to date. By examining positive functioning and psychopathology within the same study, this study is expected to contribute to a deeper understanding of these models, and may have applied implications for the prevention of depression in youth and the treatment of youth with depressive symptoms.

\section{Method}

\section{Participants}

For the first wave of data, participants between the ages of 9 and 14 (grades 5 to 8) were recruited from four elementary schools in southwestern Ontario. Nine hundred and sixty-five consent packages (see Appendix A for consent form) were sent home to the parents through the children, and 269 were returned with parental consent ( 28 percent response rate) by the deadline. However, only 198 of the children (48 percent boys, 52 percent girls) participated due to absence or lack of assent. Eighty percent of the participants were Caucasian, 10 percent were Asian, and 10 percent were of other ethnicities (consistent with the demographics of the region in which the data were collected). 
For the second wave of data, parents of participants from the first wave, who agreed to be contacted for a follow up study, were re-contacted by phone one to three years later to gain consent for their child to participate in a follow up study. Fifty-five adolescents completed the follow up study, however due to missing data, only 50 participants were included in these analyses. Of the 50 participants, 54 percent ( 27 participants) were boys, and 46 percent (23 participants) were girls. At Time 1, these participants were between the ages of 9 and $14(M=$ $11.58, S D=1.21)$, and at Time 2 they were between the ages of 10 and $17(M=13.38, S D=$ 1.46). In addition, 92 percent of the participants were Caucasian, and eight percent were of other ethnicities.

\section{Measures}

The following measures were completed at Time 1 and Time 2 .

Youth Depression. The Children's Depression Inventory (CDI; Kovacs, 1981) is a selfreport questionnaire consisting of 27 items that measure depressive symptoms in youth. In the current study, the suicide item was removed yielding only 26 items. For each item, the children were asked to choose one of three statements that best indicated their feelings. Each item is associated with a three-point scale, which consists of: 0 (no or low symptoms), 1 (mild symptoms), and 2 (severe symptoms). Therefore, higher scores indicate more symptoms of depression. For example, the children were asked to choose one of the three following statements that best represented their feelings; "I am sad once in a while" (indicating no or low symptoms), "I am sad many times" (indicating mild symptoms), or "I am sad all the time" (indicating severe symptoms). Adequate internal consistency (.80-.94) and test-retest reliability have been established for this measure (Saylor, Finch, Spirito, \& Bennett, 1984). In this study, the internal consistency at Time 1 and Time 2 was adequate $(\alpha=.70$, and $\alpha=.84$, respectively) 
and the test-restest reliability was modest $(r=.43)$.

Resilience. The Resilience Scale (RS; Wagnild \& Young, 1993) is a self-report questionnaire consisting of 25 items measuring youth's beliefs about their ability to cope with adversity (e.g., "I usually manage one way or another"; see Appendix B). Each item is measured on a 7-point Likert scale ranging from 1 (strongly disagree) to 7 (strongly agree). Higher scores indicate greater resilience. Adequate internal consistency (.76-.91) and concurrent validity (positive correlations with adaptive outcomes and negative correlation with depression) have been established for this measure (Wagnild \& Young, 1993). In this study, the internal consistency at Time 1 and Time 2 was high ( $\alpha=90$, and $\alpha=.92$, respectively) and the testrestest reliability was modest $(r=.34)$.

Schema Content. The Schema Questionnaire for Children (SQC; Stallard \& Rayner, 2005) is a self-report questionnaire consisting of 15 items that measure negative schema content in youth (e.g., "other people are better than me"; see Appendix C). Each item is measured on a 6-point Likert scale ranging from 1 (completely untrue of me) to 6 (describes me perfectly). Higher scores indicated more negative schema content. Young (1990) proposed that early maladaptive schemas (EMSs) develop during childhood to help navigate ones environment, and can later trigger depression when activated by relevant environmental stressors. Though Young (1990) originally proposed 16 early maladaptive schemas, 15 obtained psychometric support in a community sample (Schmidt, Joiner, Young, \& Telch, 1995). The SQC was designed to reflect the 15 (11 unconditional and four conditional) empirically supported early maladaptive schemas (Stallard \& Rayner, 2005). The schemas that are most central to individuals' beliefs about themselves and others are theorized to be the earliest schemas to develop and are known as unconditional schemas, whereas conditional schemas may develop later in the context of other 
relationships (Young et al., 2003). As such, and given the nature of this early adolescent sample, there was a focus on the items that reflect the unconditional early maladaptive schemas. The items were further limited to the eight of 11 items that were significantly correlated with the Young Schema Questionnaire short form (Stallard \& Rayner, 2005). Therefore, the eight unconditional early maladaptive schemas reflected in Time 1 analyses and subsequently used to predict depressive symptoms and resilience at Time 2 had themes of social isolation/alienation, mistrust/abuse, dependence/incompetence, vulnerability to harm/or illness, emotional deprivation, defectiveness/shame, entitlement/grandiosity, and failure.

Good face validity and adequate concurrent validity (with the short form Young Schema Questionnaire) and reliability have been established for this measure (Rijkeboer \& de Boo, 2010; Stallard, 2007; Stallard \& Rayner, 2005). In this study, the internal consistency at Time 1 and Time 2 was adequate ( $\alpha=.74$, and $\alpha=.81$, respectively) and the test-restest reliability was modest $(r=.51)$.

The Positive Schema Questionnaire (PSQ; Keyfitz et al., 2012) is a self-report questionnaire consisting of 36 items that measure positive schema content in youth (e.g., "I look at the bright side of things"; see Appendix D). The measure consists of five subscales (schema categories) including self-efficacy, success, trust, optimism, and worthiness. Each item is measured on a 6-point Likert scale ranging from 1 (completely untrue of me) to 6 (describes me perfectly). Higher scores indicated more positive schema content. This measure was developed as a positive schema counterpart to the SQC (Keyfitz et al., 2012). Good face validity and predictive validity have been established for this measure, as well as good internal reliability (.80-.90; Keyfitz et al., 2012). In this study, the internal consistency at Time 1 and Time 2 was very good ( $\alpha=.95$, and $\alpha=.96$, respectively) and the test-restest reliability was modest $(r=.52)$. 
Schema Organization. The Psychological Distance Scaling Task (PDST; Dozois \& Dobson, 2001a; 2001b; youth version Lumley et al., 2011) was used to measure how positive and negative schema content is organized (see Appendix E). In the computer-administered task, children are presented with a four-quadrant grid, with the x-axis (self relevance) ranging from left (not at all like me) to right (very much like me), and the y-axis (valence) ranging from top (very positive) to bottom (very negative). On each trial ( 3 practice and 28 experimental), the child was presented with an adjective in the center of the grid, and was asked to indicate the spot on the grid that best describes them. The 28 adjectives consisted of 14 positive self-referent adjectives (e.g., "caring"), and 14 negative self-referent adjectives (e.g., "mean"). The adjectives encompassed interpersonal (e.g., "helpful") and achievement (e.g. "lazy") themes which have been used by other researchers in studies of children's schemas (e.g., Hammen \& Zupan, 1984). A higher score indicates less interconnection, whereas a lower score indicates more interconnection. Adequate reliability and validity have been established for this measure in adult samples (Dozois \& Dobson, 2001a; 2001b; 2003;), and more recently in an early adolescent sample of 200 youth (Lumley et al., 2011).

\section{Procedure}

Upon receiving ethics clearance from the research ethics board at the University of Guelph and the Wellington Catholic District School Board, consent packages were sent home to the parents and were returned to school through the children. For the first wave of data, measures were administered at the child's school on netbooks with the aid of research assistants. Children were given the opportunity to assent to participate in the study before completing the measures in the mobile lab. Ten to 25 students completed the questionnaires at once, and each group of students completed the questionnaires within one hour. When the children were done, 
they were given a small toy to thank them for their participation.

The second wave of data was collected online, and the consent process needed to be reinitiated, so each parent needed to be re-contacted individually by phone. The researchers began re-contacting the parents one year following the initial study, however, the parents were often difficult to reach so this process took much longer than expected. As such, there was significant variability between the time elapsed from the initial data collection for each participant (range of 1 year, 2 months to 3 years, 2 months). If the parent was interested in having his/her child participate, the parent was sent an email containing information about the follow up study, and a consent form. Once the signed consent form was returned, the parent was sent a second email containing the link to the online study, as well as an ID number that was used to link the child's responses to his or her data collected at Time 1. The same measures as Time 1 were administered online, for each child to complete at his/her convenience. Before completing the online questionnaire, the child was prompted to assent to his/her participation. The child then proceeded to complete the tasks online. Upon study completion, each child was sent a $\$ 10$ gift certificate to a movie theater to thank him/her for participating.

\section{Results}

\section{Preliminary Analyses}

To address missing data, mean estimates for each participant were calculated and used when 15 percent or less of their data were missing per measure. Preliminary analyses examined data for normality by observing frequencies, distributions of variables, skewness and kurtosis. Consistent with what would be expected of the distribution of depressive symptoms in a community sample, the CDI was positively skewed at both time points. The interconnectivity of positive and negative schemas on the PDST (PSO and NSO) was determined by applying 
logarithmic transformations to the data, as previous research using the PDST has done (e.g., Lumley et al., 2011). In addition, there was one identified female outlier who scored over three standard deviations higher on the measure of depressive symptoms at Time 2 than the other adolescents in the sample. Nonetheless, the participant endorsed the highest possible ratings of having a good understanding of the measures and having reported honest/truthful responses, therefore, the data from that participant were included in the analyses because they were thought to be "true" data, perhaps representative of the portion of youth in community samples who suffer from severe levels of clinical levels of depressive symptoms.

Independent group t-tests indicated that there were significant differences between participants who went on to complete Time 2 measures and participants who did not complete Time 2 measures. More specifically, participants who went on to complete Time 2 measures endorsed higher levels of negative schema content $(M=38.63, S D=9.17)$ and the positive schema theme of success $(M=21.00, S D=2.50)$ at Time 1 than participants who did not go on to complete Time 2 measures ( $M=34.36, S D=11.96 ; M=19.54, S D=4.42$, respectively).

Means and standard deviations for the total sample are presented in Table 1. Intercorrelations among all central study variables are presented in Table 2. To account for the possibility of potentially confounding variables, age and sex were examined to determine whether they were related to the central study variables (i.e., schema content, schema organization, depressive symptoms, and resilience). Univariate correlations were conducted to examine age as a possible covariate. At Time 1 , positive schema content $(r=-.27, p<.05)$, worthiness $(r=-.28, p<.05)$, trust (trend level; $r=-.21, p=.08$ ), and optimism (trend level; $r=$ $-.24, p=.05)$, were negatively correlated with age, and positive schema organization $\left(r^{2}=.32, p\right.$ $<.05)$ and depressive symptoms $\left(r^{2}=.27, p<.05\right)$ were positively correlated with age. This 
suggests that at Time 1 lower age corresponded with higher positive schema content, worthiness, trust, and optimism, and lower positive schema organization and depressive symptoms. At Time 2 , negative schema organization was negatively correlated with age (trend level; $r^{2}=-.24, p=$ $.08)$, and self-efficacy was positively correlated with age $(r=.26, p<.05)$. This suggests that at Time 2 higher age corresponded with lower negative schema organization and higher selfefficacy. Given that most of the sample was Caucasian, there was not enough variability in ethnicity to examine differences in central study variables. Independent group t-tests indicated that there were no significant differences between boys and girls on any of the central study variables (all $p$ values $>.05$ ) except for the positive schema theme of worthiness which was higher among boys $(M=20.45, S D=3.22)$ than girls $(M=18.29, S D=4.31)$ at Time $1, t(47)=$ $2.01, p=.05$.

Table 1 Descriptive statistics

\begin{tabular}{lllll}
\hline & Time 1 & & Time 2 \\
\hline & $M$ & $S D$ & $M$ & $S D$ \\
\hline Negative Schema Content & 18.57 & 6.59 & 17.46 & 7.23 \\
Positive Schema Content & 92.91 & 14.40 & 93.32 & 15.27 \\
Self-Efficacy & 18.22 & 3.24 & 19.37 & 3.11 \\
Success & 21.15 & 2.77 & 21.23 & 2.92 \\
Trust & 16.61 & 4.44 & 16.08 & 4.88 \\
Optimism & 17.44 & 4.28 & 17.28 & 3.90 \\
Worth & 19.48 & 3.87 & 19.36 & 4.19 \\
Negative Schema Organization & 1.43 & .40 & 1.48 & .55 \\
Positive Schema Organization & .36 & .24 & .35 & .27 \\
Depressive symptoms & 8.06 & 7.27 & 8.65 & 8.13 \\
Resilience & 132.23 & 19.45 & 132.83 & 21.34 \\
\hline
\end{tabular}




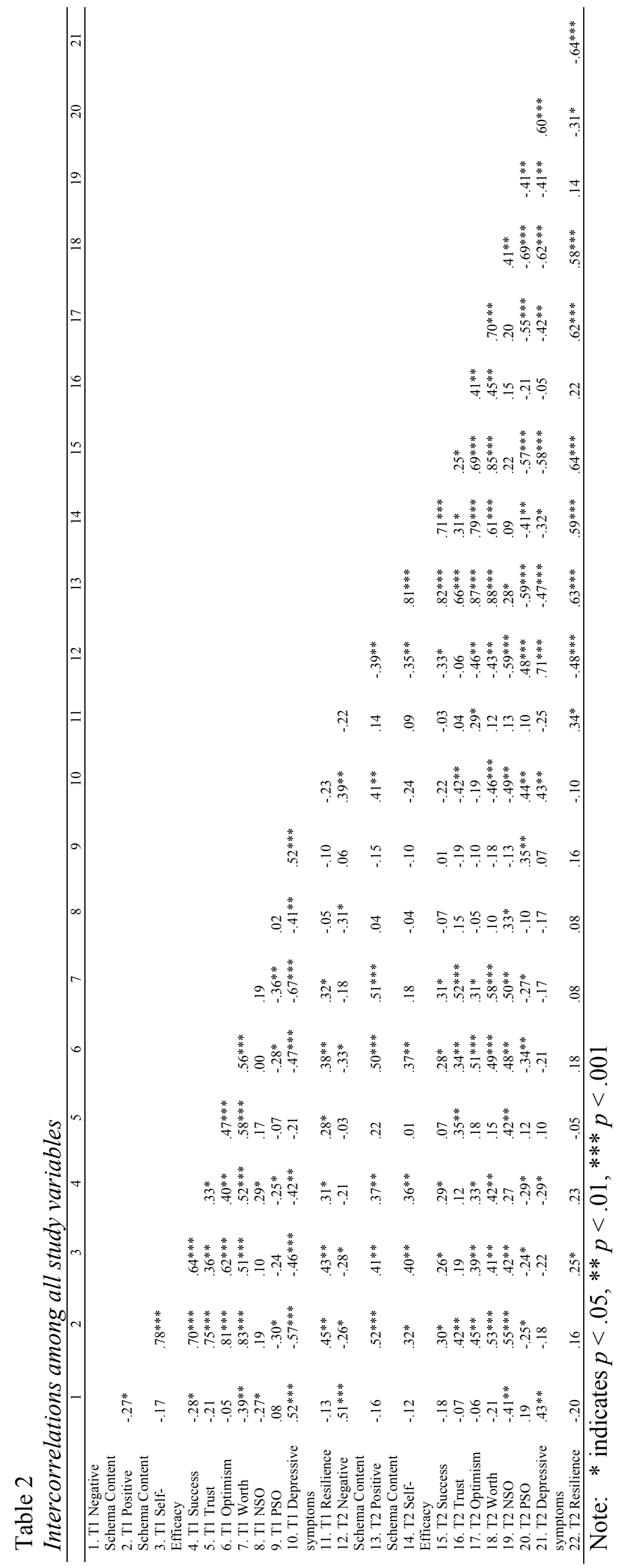




\section{Stability of Schemas in Youth}

One goal of this study was to examine the stability of positive and negative schema content and organization in early adolescence. To analyze this research question, Pearson $(r)$ correlations were computed to determine whether (and how strongly) schemas at Time 1 correlated with schemas at Time 2.

Positive Schema Content. Overall, positive schema content at Time 1 was significantly and positively correlated with positive schema content at Time $2, r=.52, p<.001$. More specifically, there was a significant and positive correlation between each of the five positive schema subscales at Time 1 and their respective subscale at Time 2 . Worthiness had the strongest correlation between Time 1 and Time $2(r=.58, p<.001)$, followed by optimism $(r=$ $.51, p<.001)$, self-efficacy $(r=.40, p<.01)$, trust $(r=.35, p<.01)$, and success $(r=.29, p<$ $.05)$. This suggests that higher scores on positive schema content overall at Time 1 corresponded to higher scores on positive schema content overall at Time 2. Similarly, higher scores on each positive schema subscale at Time 1 corresponded with higher scores on their respective counterpart subscale at Time 2.

Positive Schema Structure. Positive schema structure at Time 1 was significantly and positively correlated with positive schema structure at Time $2, r=.35, p<.01$. More specifically, the more interconnected positive schemas were at Time 1, the more interconnected these schemas were at Time 2 .

Negative Schema Content. Negative schema content at Time 1 was significantly and positively correlated with negative schema content at Time $2, r=.46, p<.01$. This suggests that higher negative schemas at Time 1 were related to higher negative schemas at Time 2.

Negative Schema Structure. Negative schema structure at Time 1 was significantly and 
positively correlated with negative schema structure at Time $2, r=.33, p<.05$. This suggests that the more interconnected negative schemas were at Time 1 the more interconnected they were at Time 2.

Overall, all of the central study variables including negative and positive schema content and structure were significantly correlated between times one and two. In addition, paired samples t-tests were conducted to examine whether any differences existed between each central study variable from Time 1 to Time 2 (see Table 3 ). There were no significant differences between negative or positive schema content overall. However, when examining positive schema themes, there was a significant difference between self-efficacy over time such that more self-efficacy was reported at Time 2 . There were no significant differences between any of the other positive schema schemes (success, trust, optimism, and worthiness). Similarly, no significant differences existed between negative or positive schema organization over time.

Table 3

Paired samples t-tests: Examining differences in variables over time $(N=50)$

\begin{tabular}{ll}
\hline & $t$ \\
\hline Negative Schema Content & 1.25 \\
Positive Schema Content & -.17 \\
Self-Efficacy & $-2.2^{*}$ \\
Success & -.17 \\
Trust & .67 \\
Optimism & .17 \\
Worth & .36 \\
Negative Schema Organization & -.64 \\
Positive Schema Organization & .28 \\
\hline
\end{tabular}

Note: * indicates $p<.05$

\section{Schemas as Prospective Predictors of Depressive Symptoms}

A second goal of this study was to examine whether schema content and organization at Time 1 prospectively predicted depressive symptoms at Time 2 . It was hypothesized that schema content and organization at Time 1 would prospectively predict mood in youth at Time 
2. To analyze this research question, bivariate correlations and partial correlations controlling for age, sex, and depressive symptoms at Time 1 were conducted to determine whether schemas at Time 1 correlated with depressive symptoms at Time 2 (see Table 4).

When examining bivariate correlations, negative schema content and some positive schema content subscales (including success, and self-efficacy and optimism at a trend level) were significant predictors of depressive symptoms at Time 2 indicating that adolescents with higher negative schema content and lower levels of some positive schema content at Time 1 reported more symptoms of depression at Time 2. In addition, it is important to note that depressive symptoms at Time 1 was also a significant predictor of depressive symptoms at Time 2, demonstrating that adolescents with more symptoms of depression at Time 1 also displayed more symptoms of depression at Time 2 .

In the multivariate context in which depressive symptoms at Time 1 were controlled for, negative schema content was found to be the only significant predictor of depressive symptoms at Time 2 indicating that adolescents with higher negative schema content at Time 1 reported more symptoms of depression at Time 2. In addition, the positive schema themes of trust and worthiness trended toward being significant predictors of depression. However, these trends were in the opposite direction hypothesized, such that adolescents with more trust and worthiness at Time 1 also experienced more symptoms of depression at Time 2. 
Table 4

Correlations and partial correlations of variables at Time 1 with depressive symptoms and resilience at Time $2(N=50)$

\begin{tabular}{lllll}
\hline & \multicolumn{2}{l}{ Bivariate correlations } & \multicolumn{2}{l}{$\begin{array}{l}\text { Partial correlations } \\
\text { Controlling for age, sex and } \\
\text { depression/resilience at Time 1 }\end{array}$} \\
\hline & $\begin{array}{l}\text { Depressive } \\
\text { symptoms }\end{array}$ & Resilience & $\begin{array}{l}\text { Depressive } \\
\text { symptoms }\end{array}$ & Resilience \\
\hline Negative Schema Content & $.43^{* *}$ & $-.20^{\mathrm{x}}$ & $.28^{*}$ & $-.30^{*}$ \\
Positive Schema Content & -.18 & .16 & .12 & -.01 \\
Self-Efficacy & $-.22^{\mathrm{x}}$ & $.25^{*}$ & .02 & .09 \\
Success & $-.29^{*}$ & $.23^{\mathrm{x}}$ & -.13 & .14 \\
Trust & .10 & -.05 & $.24^{\mathrm{x}}$ & -.19 \\
Optimism & $-.21^{\mathrm{x}}$ & .18 & -.01 & .08 \\
Worth & -.17 & .08 & $.23^{\mathrm{x}}$ & -.03 \\
Negative Schema Organization & -.17 & .08 & -.03 & .11 \\
Positive Schema Organization & .07 & .16 & -.20 & .15 \\
Depressive symptoms & $.43^{* *}$ & -.10 & & \\
Resilience & $-.25^{\mathrm{x}}$ & $.34^{*}$ & & \\
\hline
\end{tabular}

Note: ${ }^{\mathrm{x}}$ indicates trending toward significance $(p=.05$ to .09$)$

$$
* p<.05, * * p<.01
$$

\section{Schemas as Prospective Predictors of Resilience}

A third goal of this study was to examine whether schema content and organization at Time 1 could prospectively predict resilience at Time 2 . It was hypothesized that schema content and organization at Time 1 would prospectively predict resilience in youth at Time 2 . To analyze this research question, partial correlations controlling for age, sex, and resilience at Time 1 were conducted to determine whether schemas at Time 1 correlated with resilience at Time 2 (see Table 3).

When examining bivariate correlations, negative schema content (trend level) and some positive schema content themes (including self-efficacy, and success at a trend level) were significant predictors of resilience at Time 2 indicating that adolescents with lower negative schema content and higher levels of some positive schema content at Time 1 experienced more resilience at Time 2. In addition, it is important to note that resilience at Time 1 was also a 
significant predictor of resilience at Time 2 demonstrating that adolescents with more resilience at Time 1 also displayed more resilience at Time 2. When examining partial correlations controlling for age, sex, and resilience at Time 1, negative schema content was found to be the only significant predictor of resilience at Time 2 , indicating that adolescents with more negative schema content at Time 1 experienced less resilience at Time 2.

\section{Discussion}

\section{Stability of Schemas in Youth}

One goal of this study was to gain a better understanding of the stability of positive and negative schema content and organization in youth. This study found support for the stability of negative schema content in youth, replicating research findings of negative schema content stability in adults (Dozois \& Dobson, 2001a), and similar previous findings of negative cognitive style stability in adolescents (Hankin, 2008). This was the first study to examine the stability of positive schema content in an adolescent sample. The overall measure of positive schema content, and each of the five positive schema subscales were correlated with their counterpart at each time point. Also, with the exception of self-efficacy (which increased) there was no significant difference between Time 1 and Time 2 values of positive schema total or positive schema subscales. Taken together, these results suggest stability of positive schema content in adolescence.

It is possible that self-efficacy increased with age because as adolescents gain more life experience, they may feel more adept at dealing with new or difficult situations and responding to challenges and may also be given more agency by the important adults in their lives (Pajares, 2006).

In addition, this was the first longitudinal study to examine the stability of positive and 
negative schema structure in youth. While adult research has suggested that negative schema organization may be relatively stable, and positive schema organization may be less stable (Dozois \& Dobson, 2001a; Dozois 2007), positive and negative schema organization were found to be stable in this sample, and findings indicated that the interrelations among schemas were stable to a similar degree for both positive and negative schemas (i.e., one was not more stable than the other as indicated by Pearson correlations). Therefore, in addition to providing support for the stability of schema content, this study provided support for the stability of schema structure in adolescence. While adolescence is a time sometimes characterized by selfexploration and/or identity confusion (Brinthaupt \& Lipka, 2002), this study suggests that schemas, aspects of self-concept that are relevant to depressive symptoms and resilience, may be quite stable and well-formed during this developmental period. Longitudinal evidence of schema stability in adolescence may have important implications for the predictability, prevention and timing of mental health promotion to foster resilience and prevent depression amongst youth.

\section{Schemas as Prospective Predictors of Depressive Symptoms}

A second goal of this study was to examine whether schema content and organization at Time 1 could prospectively predict depressive symptoms at Time 2 . Consistent with hypotheses, negative schema content was a significant predictor of depressive symptoms such that after controlling for age, sex and depressive symptoms at Time 1, adolescents with more negative schema content at Time 1 experienced more symptoms of depression at Time 2. Although positive schema content and structure were significantly related to depressive symptoms at Time 2, contrary to hypotheses, after controlling for age, sex and depressive symptoms at Time 1 , positive schema content and schema structure were not found to be significant prospective 
predictors of depressive symptoms in this sample. Surprisingly, the positive schema themes of trust and worthiness trended toward being significant predictors of depressive symptoms in the opposite direction than hypothesized (i.e., adolescents with more trust and worthiness at Time 1 also experience more symptoms of depression at Time 2).

Examining relations between Time 1 variables and depressive symptoms at Time 2 suggests that all positive schema themes at Time 1 were associated with Time 2 depressive symptoms in the expected directions, except for the theme of trust. Since depressive symptoms at Time 1 account for a large portion of variance in depressive symptoms at Time 2, once controlled for, these schemas may relate in unexpected directions with this remaining variance. This was surprising as the positive schema theme of trust has previously been conceptualized as a strength, and was negatively related to depression in a cross-sectional sample of adolescents (Keyfitz et al., 2012). This finding may be in line with personality predispositions that have previously been linked to depression. For example, individuals who are high on Beck's (1983) construct of sociotropy (i.e., who are highly motivated to form and maintain relationships) and on Blatt and Zuroff's (1992) personality predisposition of dependency (i.e., who rely on others to maintain their sense of well-being through closeness and intimacy) are theorized to be vulnerable to depressive symptoms when exposed to negative interpersonal events. Therefore, it may be the case that youth who strongly value connectedness and interpersonal trust, may be at a higher risk for symptoms of depression over time due to highly valuing relationships, which may create vulnerability when interpersonal stress arises.

\section{Schemas as Prospective Predictors of Resilience}

A third goal of this study was to examine whether schema content and organization at Time 1 could prospectively predict resilience at Time 2 . Consistent with hypotheses, negative 
schema content was a significant predictor of resilience such that adolescents with more negative schema content at Time 1 experienced less resilience at Time 2, and adolescents with less negative schema content at Time 1 experienced more resilience at Time 2 . Contrary to hypotheses, positive schema content and schema structure were not found to be significant longitudinal predictors of resilience in this sample.

While resilience was conceptualized as one's ability to adaptively cope with adversity, it was difficult to examine adaptive outcomes given the lack of contextual information (e.g., information regarding adversity). In addition, while the youth's perception of how they cope with adversity is interesting and important for understanding well being, it may be insightful to examine resilience in other ways beyond self-report.

Similar to the relation between positive schemas and depressive symptoms, examining relations between Time 1 variables and resilience at Time 2 suggests that all positive schema themes at Time 1 were associated with Time 2 resilience in the expected directions (despite some non-significant correlations), except for the theme of trust. Interestingly, the positive schema theme of self-efficacy had the strongest univariate correlation with resilience, and had previously surfaced as the theme with the strongest association with resilience in cross-sectional research (Keyfitz et al., 2012). Since resilience at Time 1 accounts for a large portion of variance in resilience at Time 2, these schemas may not relate with the remaining variance after controlling for resilience. Similar explanations regarding the relation between trust and depressive symptoms may apply to resilience as well.

Taken together these results suggest that negative cognitive schemas are quite stable in adolescence and also that even when controlling for Time 1 depressive symptoms or resilience, it is the negative schemas that seem to most strongly predict longitudinal risk for later depressive 
symptoms and lower levels of resilience in youth. These results are consistent with previous findings from adult research, which suggest that negative schemas may be more stable than positive schemas (Dozois \& Dobson, 2001a; Dozois 2007). If these results are replicated in larger and more diverse samples, it could suggest that negative schemas are most problematic for promoting positive development and should perhaps be the primary cognitive focus of early intervention and treatment in youth.

While there were no significant sex differences in symptoms of depression in this adolescent sample, much research has examined sex differences in this age group. A metaanalysis of 310 samples of children age 8 to 16 found that while boys and girls depression scores are similar until age 13 (with girls scoring slightly lower than boys during childhood) starting at age 13, girls tend to exhibit more depression symptoms than boys (Twenge \& Nolen-Hoeksema, 2002). Since the majority of the current sample was under the age of 14 at Time 1 , the lack of sex differences on depression symptoms at Time 1 is consistent with the findings of the metaanalysis. In addition, Twenge and Nolen-Hoeksema (2002) found that boys' depression scores on the CDI remained relatively stable between the ages of 8 and 16, whereas girls scores were stable between the ages of 8 and 11, and increased between the ages of 12 and 16. Interestingly, the only central study variable that trended toward a significant difference between boys and girls at Time 1 was worthiness, such that boys scored higher than girls. Worthiness has previously been identified as the positive schema theme most predictive of depression in crosssectional research (Keyfitz et al., 2012), and may mediate the relation between sex and symptoms of depression. However, sufficient evidence to make such conclusions is currently lacking, and important sex differences need to be explored in future research. 


\section{Limitations}

While the depressotypic cognitive pattern previously evidenced in adults (Dozois, 2007; Dozois \& Dobson, 2001a; 2001b; 2003, Dozois \& Frewen, 2006) and in an early adolescent cross-sectional sample (Lumley et al., 2011) and the hypothesized cognitive pattern for increased resilience was not fully supported in this longitudinal study, it is important to note some of the limitations of the current study which temper interpretation and inform the design of future research addressing similar questions. First, this study used a community sample of youth who are generally not experiencing clinical levels of depressive symptoms. Results from such a sample may differ in meaningful ways from a clinical sample of youth, who experience higher levels of depressive symptoms as well as other forms of psychopathology. In addition, the participants given parental consent to participate in both waves of data may differ in meaningful ways from adolescents who were not given parental consent (e.g., parents of children with emotional difficulties may have been less likely to consent). Results may therefore not be generalizable to adolescents more broadly.

Second, this sample was quite small, and consequently statistical power was rather limited in evaluating the sample as a whole. As such, the sample size was also not large enough to assess sex and age differences, and should be explored more carefully in future research. It is important to assess age effects and sex differences in adolescent research of depressive symptoms and resilience, because this is the developmental period when sex differences begin to emerge. The significant results found in this study (i.e., the stability of schemas, and that negative schemas were the strongest predictor of depressive symptoms and resilience) may capture the most salient or relevant schema findings in an adolescent sample. However, since some additional analyses trended toward significance, additional important findings may be 
elucidated in a larger sample size. In addition, since the participants who went on to complete Time 2 measures endorsed higher levels of negative schema content at Time 1 than participants who did not go on to complete Time 2 measures, it is possible that the nature of the sample may have contributed to the finding that negative schemas were the strongest predictor of depressive symptoms and resilience.

Third, while this study integrated psychopathology and positive psychology constructs, cognitive theories are inherently diathesis-stress theories and this study was limited by not including any measures of stressful life events and difficulties, or positive life events. Since diathesis-stress theories assert that depression results from an interaction between a cognitive vulnerability factor and an environmental stressor such as a negative life event (Ingram, Miranda, \& Segal, 1998), information about life events may have contributed important information about the link between schemas, depressive symptoms, and resilience. In addition, this study relied solely on self-report measures to evaluate schema content, organization, symptoms of depression, and resilience. Results on self-report measures are subject to numerous self-report and memory biases and may be influenced by factors such as mood and social desirability (Paulhus \& Vazire, 2009). In addition, it may be difficult for adolescents to selfreport on schemas, symptoms of depression, and resilience because they may lack the awareness necessary to assess internal beliefs (Zeman, Klimes-Dougan, Cassano, \& Adrian, 2007). However, adolescents may be considered to be the best reporters of their depressive symptoms (Saylor, Finch, Baskin, Furey, \& Kelly, 1984).

Fourth, since the Time 2 data was collected online, and the consent process needed to be reinitiated, each participant needed to be re-contacted individually by phone. This process took much longer than anticipated and it was difficult to reach and coordinate with families. As such, 
there was a lot of variability between the time elapsed from the initial data collection for each participant. Some participants completed the Time 2 measures a year following Time 1, whereas other participants completed the measures up to three years after the initial collection. Ideally, all participants would have completed Time 2 measures at a similar interval from Time 1. It would also have been ideal to collect at least three time points to examine the stability of schemas more carefully. Data at three time points would allow for more robust statistical analyses to be used (e.g., latent growth curve analysis). In particular, with two time points, correlation and regression analyses always provides a perfect linear fit; hence, at least three time points are needed to more precisely determine the accuracy of the fit. Despite these limitations, this first study of the stability of positive schemas in youth and provides novel, albeit preliminary, evidence about schemas may remain quite stable during what is considered by some a period of considerable shifts in self-concept and identity constructs (Brinthaupt \& Lipka, 2002).

\section{Future Directions and Implications}

Future research should aim to examine the stability of schemas in a larger sample and examine links between schemas, depressive symptoms, and resilience in younger, clinical, and more diverse samples over multiple time points. Similar to the studies of adults with depression (Dozois, 2007; Dozois \& Dobson, 2001a), positive schema organization may not be stable over time in clinical samples of youth. Consistent with the adult literature (Dozois, 2007; Dozois \& Dobson, 2001a), and recent cross-sectional evidence suggesting the depressotypic pattern of schema organization may exist in adolescents (Dozois et al. 2012; Lumley et al., 2011), positive schemas may be expected to become more tightly interconnected when depressive symptoms remit, whereas negative schema organization may remain relatively stable. In addition, future 
research needs to carefully examine sex differences in the models examined here. Understanding the etiology of depression in diverse samples and identifying adaptive and maladaptive schemas as early as possible are crucial components of promoting resilience, reducing the prevalence of depressive symptoms, and treating depression effectively. While the results of this study suggest that schemas may already be well established in adolescence, earlier assessment approaches and identification are important for early intervention. Since children have a lot of neuroplasticity, and their brains have the capacity to adapt easily to new experiences, interventions may be more effective if started at an early age.

In addition, future research in this area can have important clinical and applied implications. If these results are replicated in future research, it appears that a focus on identifying and challenging negative cognitive schemas with themes such as defectiveness/shame, dependence/incompetence, and vulnerability to harm, may be worthwhile for protecting against future depressive symptoms and also for promoting more self-reported resilience in youth. Indeed, the current study supports the primary focus of identifying and modifying maladaptive schemas in cognitive behaviour therapy for youth. Since negative schemas appear to be salient long term predictors of depressive symptoms in a community sample of youth (most of whom are likely not accessing mental health services), finding ways to better identify and challenge negative schemas within family and school contexts might be an important future direction for all youth.

Overall, this study provides preliminary evidence that both positive and negative schema content and organization may be quite stable in a community sample of youth. While negative schema content appears to be the best longitudinal predictor of depression and resilience in this study, future research is needed to examine the stability of schemas, and schemas as prospective 
predictors of depression and resilience in more diverse samples. Additional empirical information regarding schemas in youth may have important implications for promoting positive functioning and reducing negative functioning. 


\section{References}

Abela, J. R. Z., \& Hankin, B. L. (Eds.). (2008). Handbook of depression in children and adolescents. New York, NY: Guilford Press.

Abela, J. R. Z., \& Sullivan, C. (2003). A test of Beck's cognitive diathesis-stress theory of depression in early adolescents. Journal of Early Adolescence, 23(4), 384-404.

Abramson, L. Y., Metalsky, G. I., Alloy, L. B., 1989. Hopelessness depression: A theory-based subtype of depression. Psychological Review, 96(2), 358-372.

Abramson, L. Y., Seligman, M. E. P., \& Teasdale, J. D. (1978). Learned helplessness in humans: Critique and reformulation. Journal of Abnormal Psychology, 87(1), 49-74.

Beck, A. T. (1967). Depression. New York, NY: Harper and Row.

Beck, A. T. (1987). Cognitive models of depression. Journal of Cognitive Psychotherapy, 1(1), $5-37$.

Brinthaupt, T. M., \& Lipka, R. P. (2002). Understanding early adolescent self and identity: An introduction. In Lipka, R. P. \& Brinthaupt, T. M. (Eds). Understanding early adolescent self and identity: Applications and interventions pp. 1-21). Albany: State University of New York Press.

Bohon, C., Stice, E., Burton, E., Fudell, M., \& Nolen-Hoeksema, S. (2008). A prospective test of cognitive vulnerability models of depression with adolescent girls. Behaviour Therapy, 39, 79-90.

Carter, J. S., \& Garber, J. (2011). Predictors of the first onset of a major depressive episode and changes in depressive symptoms across adolescence: stress and negative cognitions. Journal of Abnormal Psychology, 120(4), 779-796. 
Clark, D. A., Beck, A. T., \& Alford, B. A. (1999). Scientific foundations of cognitive theory and therapy of depression. New York, NY: Wiley.

Collins, A. M., \& Loftus, E. F. (1975). A spreading-activation theory of semantic processing. Psychological Review, 82(6), 407-428.

Dozois, D. J. A. (2007). Stability of negative self-structures: A longitudinal comparison of depressed, remitted, and nonpsychiatric controls. Journal of Clinical Psychology, 63(4), 319-338.

Dozois, J. A., \& Beck, A. T. (2008). Cognitive schemas, beliefs and assumptions. In K. S. Dobson \& D. J. A. Doizois (Eds.), Risk factors in depression (pp. 121-143). San Diego, CA: Elsevier Academic Press.

Dozois, D. J. A., \& Dobson, K. S. (2001a). A longitudinal investigation of information processing and cognitive organization in clinical depression: Stability of schematic interconnectedness. Journal of Consulting and Clinical Psychology, 69(6), 914-925.

Dozois, D. J. A., \& Dobson, K. S. (2001b). Information processing and cognitive organization in unipolar depression: Specificity and comorbidity issues. Journal of Abnormal Psychology, 110(2), 236-246.

Dozois, D. J. A., \& Dobson, K. S. (2003). The structure of the self-schema in clinical depression: Differences related to episode recurrence. Cognition and Emotion, 17(6), 933-941.

Dozois, D. J. A., Eichstedt, J. A., Collins, K. A., Phoenix, E, \& Harris, K. (2012). Core beliefs, self-perception, and cognitive organization in depressed adolescents. International Journal of Cognitive Therapy, 5(1), 99-112. 
Dozois, D. J. A, \& Frewen, P. A. (2006). Specificity of cognitive structure in depression and social phobia: A comparison of interpersonal and achievement content. Journal of Affective Disorders, 90, 101-109.

Fergusson, D. M., Horwood, L. J., Ridder, E. M., \& Beautrais, A. L. (2005). Subthreshold depression in adolescence and mental health outcomes in adulthood. Archives of General Psychiatry, 62, 66-72.

Garber, J., Weiss, B., \& Shanley, N. (1993). Cognitions, depressive symptoms, and development in adolescents. Journal of Abnormal Psychology, 102(1), 47-57.

Gencoz, T., Voelz, Z. R., Gencoz, F., Pettit, J. W., \& Jointer, T. E. (2001). Specificity of information processing styles to depressive symptoms in youth psychiatric inpatients. Journal of Abnormal Child Psychology, 29(3), 255-262.

Georgiades, K., Lewinsohn, P. M., Monroe, S. M., \& Seeley, J. R. (2006). Major depressive disorder in adolescence: The role of subthreshold symptoms. Journal of the American Academy of Child \& Adolescent Psychiatry, 48(8), 936-944.

Gonzalez-Tejera, G., Canino, G., Ramirez, R., Chavez, L., Shrout, P., Bird, H., Bravo, M., Martinez-Taboas, A., Ribera, J., \& Bauermeister, J. (2005). Examining minor and major depression in adolescents. Journal of Child Psychology and Psychiatry, 46(8), 888-899.

Gotlib, I. H., Lewinsohn, P. M., \& Seeley, J. R. (1995). Symptoms versus a diagnosis of depression: Differences in psychosocial functioning. Journal of Consulting and Clinical Psychology, 63, 90-100.

Haeffel, G. J., \& Grigorenko, E. L. (2007). Cognitive vulnerability to depression: Exploring risk and resilience. Child and Adolescent Psychiatric Clinics of North America, 16, 435448. 
Hammen, C., \& Zupan, B. A. (1984). Self-schemas, depression, and the processing of personal information in children. Journal of Experimental Child Psychology, 37, 598-608.

Hankin, B. L. (2008). Stability of cognitive vulnerability to depression: A short-term prospective multiwave study. Journal of Abnormal Psychology, 117(2), 324-333.

Hankin, B. L., \& Abela, J. R. Z. (2005). Depression from childhood through adolescence and adulthood: A developmental vulnerability-stress perspective. In B. L. Hankin \& J. R. Z. Abela (Eds.), Development of psychopathology: A vulnerability-stress perspective (pp. 245-288). Thousand Oaks, CA: Sage.

Hankin, B. L., Abramson, L. Y., Moffitt, T. E., Silva, P. A., McGee, R., \& Angell, K. E. (1998). Development of depression from preadolescence to young adulthood: Emerging gender differences in a 10-year longitudinal study. Journal of Abnormal Psychology, 107(1), $128-140$.

Hankin, B. L., Lakdawalla, Z., Lee, A., Grace, D., \& Roesch, L. (2004). Cognitive vulnerabilities for emotional distress in adolescence: Disentangling the comorbidity of depression and anxiety in a multi-wave prospective study. In B. L. Hankin, \& J. R. Z. Abela (Co-chairs), Depression and anxiety: Issues of specificity and comorbidity. Symposium conducted at the 38th annual meeting of the Association for Advancement of Behaviour Therapy, New Orleans, LA.

Hjemdal, O., Aune, T., Reinfjell, T., Stiles, T. C., \& Friborg, O. (2007). Resilience as a predictor of depressive symptoms: A correlational study with young adolescents. Clinical Child Psychology and Psychiatry, 12, 91-104. 
Hjemdal, O., Vogel, P. A., Solem, S., Hagen, K., \& Stiles, T. C. (2011). The relationship between resilience and levels of anxiety, depression, and obsessive-compulsive symptoms in adolescents. Child Psychology and Psychotherapy, 18, 314-321.

Ingram, R. E. (1984). Toward an information-processing analysis of depression. Cognitive Therapy and Research, 8(5), 443-478.

Ingram, R. E., Miranda, J., \& Segal, Z. V. (1998). Cognitive vulnerability to depression. New York, NY: Guilford.

Kandel, D. B., \& Davies, M. (1986). Adult sequelae of adolescent depressive symptoms. Archives of General Psychiatry, 43, 255-262.

Kessler, R. C., Avenevoli, S., \& Merikangas, K. R. (2001). Mood disorders in children and adolescents: An epidemiologic perspective. Biological Psychiatry, 49, 1002-1014.

Keyfitz, L., Lumley, M. N., Hennig, K. H., \& Dozois, D. J. A. (2012). The role of positive schemas in child psychopathology and resilience. Cognitive Therapy and Research, 111.

Kim-Cohen, J., Caspi, A., Moffitt, T. E., Harrington, H., Milne, B. J., \& Poulton, R. (2003). Prior juvenile diagnoses in adults with mental disorder: Developmental follow-back of a prospective-longitudinal cohort. Archives of General Psychiatry, 60, 709-717.

Kovacs, M. (1981). Rating scales to assess depression in school-aged children. Acta Paedopsychiatrica, 46, 305-315.

Kovacs, M. (1996). Presentation and course of major depressive disorder during childhood and later years of the life span. Journal of the American Academy of Child and Adolescent Psychiatry, 35, 705-715. 
Kovacs, M., Feinberg, T. L., Crouse-Novak, M., Paulauskas, S. L., Pollock, M., \& Finkelstein, R. (1984). Depressive disorders in childhood. II. A longitudinal study of the risk for a subsequent major depression. Archives of General Psychiatry, 41, 643-649.

Lewinsohn, P. M., Joiner Jr., T. E., \& Rohde, P. (2001). Evaluation of cognitive diathesis-stress models in predicting major depressive disorder in adolescents. Journal of Abnormal Psychology, 110(2), 203-215.

Lewinsohn, P. M., Pettit, J. W., Joiner Jr., T. E., \& Seeley, J. R. (2003). The symptomatic expression of major depressive disorder in adolescents and young adults. Journal of Abnormal Psychology 112(2), 244-252.

Lewinsohn, P. M., Rohde, P., \& Seeley, J. R. (1998). Major depressive disorder in older adolescents: Prevalence, risk factors, and clinical implications. Child Psychology Review, 18(7), 765-794.

Lewinsohn, P. M., Rohde, P., Seeley, J. R., \& Fischer, S. A. (1993). Age-cohort changes in the lifetime occurrence of depression and other mental disorders. Journal of Abnormal Psychology, 102(1), 110-120.

Lumley, M. N., Dozois, D. J. A., Hennig, K. H., \& Marsh, A. (2011). Cognitive organization, perceptions of parenting and depressive symptoms in early adolescence. Cognitive Therapy and Research, 1-12.

Lumley, M. N., \& Harkness, K. L. (2007). Specificity in the relations among childhood adversity, early maladaptive schemas, and symptom profiles in adolescent depression. Cognitive Therapy and Research, 31(5), 639-657.

Mak, W. W. S., Ng, I. S. W., \& Wong, C. C. Y. (2011). Resilience: Enhancing well-being through the positive cognitive triad. Journal of Counseling Psychology, 58(4), 610-617. 
Masten, A. S. (2001). Ordinary magic: Resilience processes in development. American Psychologist, 56, 227-238.

Masten, A. S. (2007). Resilience in developing systems: Progress and promise as the fourth wave rises. Development and Psychopathology, 19, 921-930.

Masten, A. S. (2011). Resilience in children threatened by extreme adversity: Frameworks for research, practice, and translational synergy. Development and Psychopathology, 23, 493-506.

McClain, L., \& Abramson, L. (1995). Self-schemas, stress, and depressed mood in college students. Cognitive Therapy and Research, 19(4), 419-432.

Pajares, F. (2006). Self-efficacy during childhood and adolescence: Implications for teachers and parents. In T. Urda \& F. Pajares (Eds.), Self-efficacy beliefs of adolescents (pp. 339367). Greenwich, CT: Information Age Publishing.

Paulhus, D. L., \& Vazire, S. (2009). The self-report method. In R. W. Robins, R. C. Fraley, R. F. Krueger (Eds.), Handbook of research methods in personality psychology (pp. 224239). New York, NY: Guilford.

Rijkeboer, M. M., \& de Boo, G. M. (2010). Early maladaptive schemas in children: Development and validation of the Schema Inventory for Children. Journal of Behavior Therapy and Experimental Psychiatry, 41, 102 -109.

Rutter, M., Kim-Cohen, J., Maughan, B. (2006). Continuities and discontinuities in psychopathology between childhood and adult life. Journal of Child Psychology and Psychiatry, 47(3-4), 276-295. 
Saylor, C. F., Finch, A. J., Baskin, C. H., Furey, W., \& Kelly, M. M. (1984). Construct validity for measures of childhood depression: Application of multitrait-multimethod methodology. Journal of Consulting and Clinical Psychology, 52(6), 977-985.

Saylor, C. F., Finch, A. J., Spirito, A., \& Bennett, B. (1984). The children's depression inventory: A systematic evaluation of psychometric properties. Journal of Consulting and Clinical Psychology, 52(6), 955-967.

Schmidt, N. B., Joiner, T. E., Young, J. E., \& Telch, M. J. (1995). The Schema Questionnaire: Investigation of psychometric properties and the hierarchical structure of a measure of maladaptive schemas. Cognitive Therapy and Reseach, 19, 295-321.

Stallard, P. (2007). Early maladaptive schemas in children: Stability and differences between a community and a clinically referred sample. Clinical Psychology and Psychotherapy, 14, $10-18$

Stallard, P., \& Rayner, H. (2005). The development and preliminary evaluation of a schema questionnaire for children (SQC). Behavioural and Cognitive Psychotherapy, 3(2), 217224.

Timbremont, B., \& Braet, C. (2004). Cognitive vulnerability in remitted depressed children and adolescents. Behaviour Research and Therapy, 42, 423-437.

Twenge, J. M., \& Nolen-Hoeksema, S. (2002). Age, gender, race, socioeconomic status, and birth cohort differences on the Children's Depression Inventory: A meta-analysis. Journal of Abnormal Psychology, 111(4), 578-588.

Wagnild, G. M., \& Young, H. M. (1993). Development and psychometric evaluation of the Resilience Scale. Journal of Nursing Measurement, 1, 165-178. 
Wood, A. M., \& Tarrier, N. (2010). Positive clinical psychology: A new vision and strategy for integrated research and practice. Clinical Psychology Review, 30(7), 819-829.

Young, J. (1990). Cognitive therapy for personality disorders: A schema focused approach. Sarasota, FL: Professional Resource Exchange, Inc.

Young, J. E., Klosko, J. S., \& Weishaar, M. E. (2003). Schema therapy: Conceptual model. In J. E. Young, J. S. Klosko, \& M. E. Weishaar (Eds.), Schema therapy: A practitioner's Guide (pp. 1-62). NY, NY: Guilford Press.

Zeman, J., Klimes-Dougan, B., Cassano, M., \& Adrian, M. (2007). Measurement issues in emotion research with children and adolescents. Clinical Psychology: Science and Practice, 14(4), 377-401. 
Appendix A

Consent Form

\section{UNIVERSITY}

\section{COLLEGE OF SOCIAL AND APPLIED HUMAN SCIENCES \\ Department of Psychology \\ Parent/ Legal Guardian Information and Consent Form \\ Building Healthy Relationships Project:}

\author{
Dr. Karl Hennig \\ Department of Psychology \\ voice: (519) 824-4120 ext. 53558 \\ fax: (519) 837-8629 email: \\ khennig@uoguelph.ca
}

\author{
Dr. Margaret Lumley \\ Department of Psychology \\ voice: (519) 824-4120 ext. 56798 \\ fax: (519) 837-8629 e- \\ mail:mlumley@uoguelph.ca
}

Introduction: Youth and their parents are concerned about personal and interpersonal problems children experience as they grow up. As you likely know, these problems may have a strong negative effect on how well children do in school, socially, and later in life. The Wellington Catholic District School Board in conjunction with the University of Guelph will be administering a pilot curriculum program addressing peer-relationship challenges associated with middle childhood and early adolescence. The current research project is to help us to understand the difficulties that youth report facing. Results will be used to inform our understanding of personal and interpersonal problems and to inform future school programs.

Procedure: We are asking that parents give permission for their youth to complete a confidential questionnaire package, which will be completed on-line during one regular class block. The questionnaire package inquires about problems as well as strengths, including questions about self-esteem (e.g., "I am a good friend") and wellbeing (e.g., "How happy do you feel?" "How worried are you?" "How often do you do what you are told?", "My mother makes me feel better after talking over my worries with me"). To gain an additional perspective, we would request that you as the parent/legal guardian complete a brief 1-page questionnaire. Within the next year or so, we would also like repeat the study and we additionally request your consent to contact you in the future to invite your youth's participation in this optional follow-up component of the project. There are no known physical or social risks of participating in this research.

Questions about self-esteem and wellbeing might upset some children, however, we believe this risk is minimal given the child-friendly approach of our research team and the measures that we use. In our experience, young people have enjoyed participating in similar projects, however, participating in this study may not directly benefit your child. Children will be offered an edible treat or yo-yo to thank them for their participation. Parents who return the questionnaire will be entered into a draw to win one of five $\$ 30.00$ gift certificates.

Your child will be told that he or she has a choice whether or not to participate and will also be told that he or she may withdraw from the study or choose not to answer a particular question at any time, without penalty. Withdrawal or refusal to answer questions will not influence any 
privileges or resources that your child receives from the school. If students withdraw, their data will be destroyed.

Confidentiality: We will be collecting identifying information on the youth, but such information will not be attached to the other measures completed. All information provided is strictly confidential and will be used for research purposes. We will store the data files indefinitely for future analysis. With one exception, schools will not have access to any information we collect. In the event that a youth reports significant distress or anger/aggressiveness, we will follow-up to contact you as a parent/guardian and the school to discuss what resources there are to assist the youth. We will also be providing school personnel and interested parents with the major results of the study at an information night. Like you, we are interested in the wellbeing of youth and helping them to succeed personally, socially, and academically.

This project has been reviewed and received ethics clearance by the Research Ethics Board of the University of Guelph and the Wellington Catholic District School Board (WCDSB). If you have any questions or concerns regarding your family's rights or treatment as participant(s) in the project, you may contact Sandy Auld in the Research Ethics Board at the University of Guelph at 519-824-4120 ext. 56606 (reb@uoguelph.ca), or Dr. Karl Hennig and Dr. Margaret Lumley, whose contact information is listed above.

\section{CONSENT FORM: BUILDING HEALTHY RELATIONSHIPS PROJECT}

\section{Please return to your child's classroom teacher}

I (the parent/guardian) consent to my son/daughter's participation in the "Building Healthy Relationships Project"

I (the parent/guardian) agree to complete a brief 1-page questionnaire.

I (the parent/guardian) consent to University researchers contacting us to invite participation in the 1-year optional follow-up component of the study.

\section{Child's teacher:}

(Child's name: Please Print) (Date)

Child's Date of Birth: up invite - OPTIONAL)

(Parent/ Legal Guardian Name and Signature)

Your phone \#: (for the 1-year follow- 


\section{Appendix B}

\section{Resilience Scale}

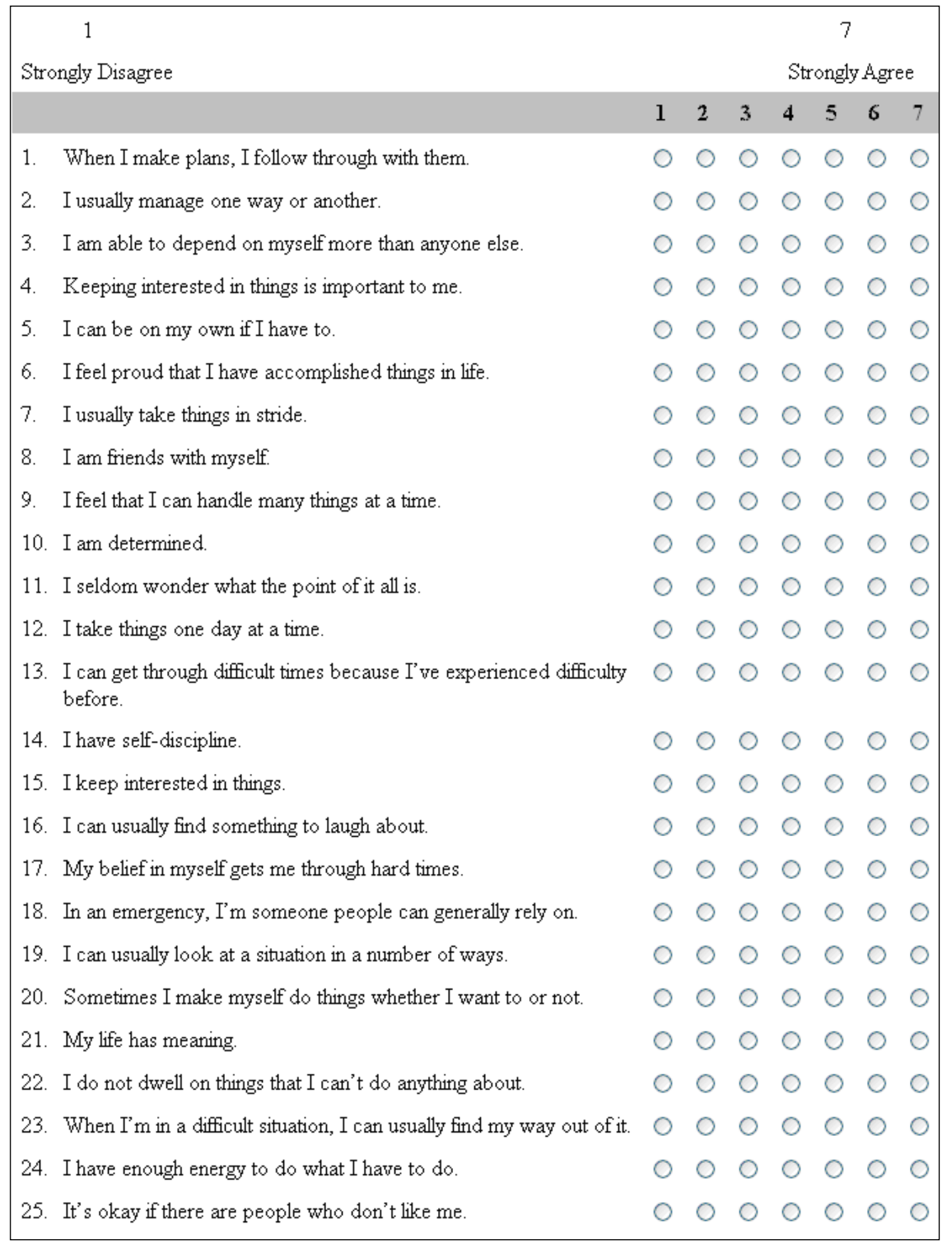




\section{Appendix C}

\section{Schema Questionnaire for Children}

\begin{tabular}{|c|c|c|c|c|c|c|}
\hline \multirow{2}{*}{ Completely untrue of me } & \multicolumn{6}{|c|}{$\begin{array}{c}6 \\
\text { Describes me perfectly }\end{array}$} \\
\hline & 1 & 2 & 3 & 4 & 5 & 6 \\
\hline 1. It is important to be better than others at everything I do & O & 0 & 0 & 0 & 0 & 0 \\
\hline 2. Other people are better than me & O & 0 & 0 & 0 & 0 & 0 \\
\hline 3. No one loves or cares about me & O & 0 & 0 & 0 & 0 & 0 \\
\hline $\begin{array}{l}\text { 4. It is important that my parents or caregivers are involved in everything I } \\
\text { do }\end{array}$ & 0 & 0 & 0 & 0 & 0 & O \\
\hline 5. I am not responsible for what I do or say & O & 0 & 0 & 0 & 0 & 0 \\
\hline 6. I am a failure & O & 0 & 0 & 0 & 0 & 0 \\
\hline 7. I am more important and special than others & 0 & 0 & 0 & 0 & $\mathrm{O}$ & 0 \\
\hline 8. People will be cross or upset if I say the things I really want to say & O & 0 & $\mathrm{O}$ & 0 & $\mathrm{O}$ & 0 \\
\hline 9. I must not show my feelings to others & O & 0 & 0 & 0 & 0 & 0 \\
\hline $\begin{array}{l}\text { 10. It is more important to put other people's wishes and ideas before my } \\
\text { own }\end{array}$ & 0 & 0 & 0 & 0 & $\mathrm{O}$ & 0 \\
\hline 11. Others are out to get or hurt me & 0 & 0 & 0 & 0 & $\mathrm{O}$ & 0 \\
\hline 12. No one understands me & $\mathrm{O}$ & 0 & 0 & 0 & 0 & 0 \\
\hline 13. People I love will never be there for me & 0 & 0 & 0 & 0 & 0 & 0 \\
\hline 14. I need other people to help me get by & O & 0 & 0 & 0 & 0 & O \\
\hline 15. Bad things happen to me & 0 & 0 & 0 & 0 & $\mathrm{O}$ & 0 \\
\hline
\end{tabular}




\section{Appendix D}

\section{Positive Schema Questionnaire}

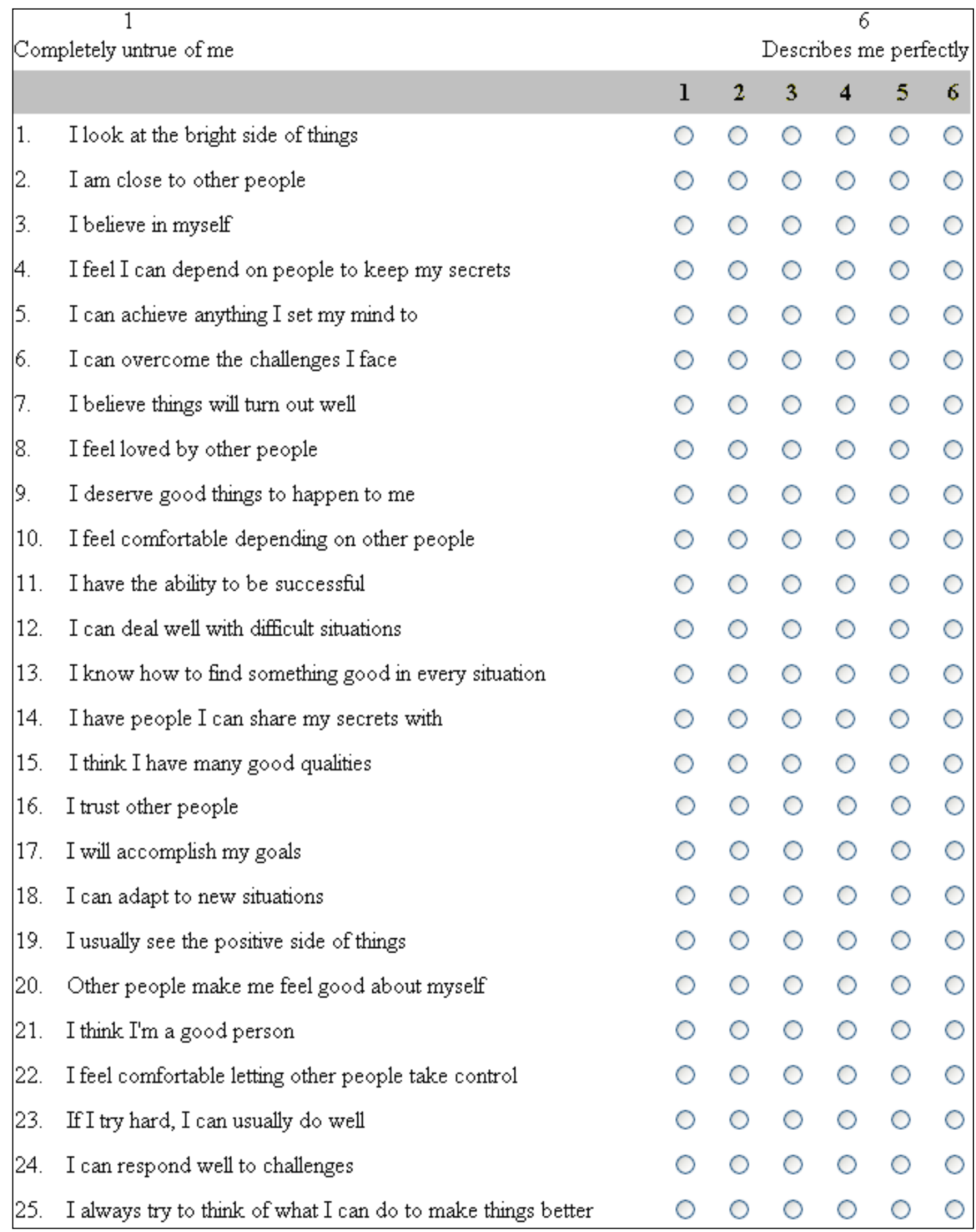




\begin{tabular}{|lllllll|}
\hline 26. Other people understand me & 0 & 0 & 0 & 0 & 0 & 0 \\
27. I value many things about myself & 0 & 0 & 0 & 0 & 0 & 0 \\
28. Other people have my best interest in mind & 0 & 0 & 0 & 0 & 0 & 0 \\
29. I do well when I try my best & 0 & 0 & 0 & 0 & 0 & 0 \\
30. When I am challenged, I know I can handle it & 0 & 0 & 0 & 0 & 0 & 0 \\
31. When things are bad I can still think of something good & 0 & 0 & 0 & 0 & 0 & 0 \\
32. Other people care about me & 0 & 0 & 0 & 0 & 0 & 0 \\
33. I value myself & 0 & 0 & 0 & 0 & 0 & 0 \\
34. I feel comfortable telling people important things about myself & 0 & 0 & 0 & 0 & 0 & 0 \\
35. If I try, I will succeed & 0 & 0 & 0 & 0 & 0 & 0 \\
36. I can deal with tough things & 0 & 0 & 0 & 0 & 0 & 0 \\
\hline
\end{tabular}


Appendix E

Psychological Distance Scaling Task

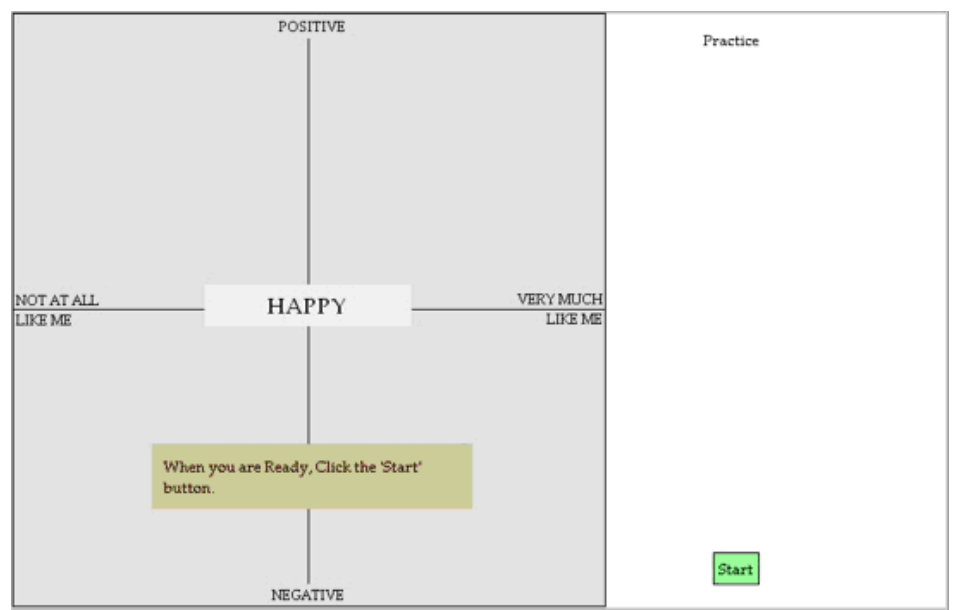

Word List:

mywords[4] = "CARING";

mywords[5] = "JOYFUL";

mywords[6] = "KIND";

mywords[7] = "NICE";

mywords[8] = "POPULAR";

mywords[9] = "GOOD";

mywords[10] = "FUNNY";

mywords[11] = "HELPFUL";

mywords[12] = "FRIENDLY";

mywords[13] = "TALENTED";

mywords[14] = "SMART";

mywords[15] = "BRAVE";

mywords[16] = "PROUD";

mywords[17] = "CLEVER";

mywords[18] = "MEAN";

mywords[19] = "GRUMPY";

mywords[20] = "ALONE";

mywords[21] = "SHY";

mywords[22] = "UNLOVED";

mywords[23] = "UNWANTED";

mywords[24] = "BORING";

mywords[25] = "UGLY";

mywords[26] = "LONELY";

mywords[27] = "LAZY";

mywords[28] = "STUPID";

mywords[29] = "EMBARRASSED";

mywords[30] = "TERRIBLE";

mywords[31] = "BAD " 